\section{REFERENCES}

1. Check Hayden E. Ebola outbreak thrusts MSF into new roles. Nature. 2015;522(7554):18-19. http://dx.doi.org/10.1038/522018a.

2. Kodama Y, Oikawa T, Hayashi K, et al. Impact of natural disaster combined with nuclear power plant accidents on local medical services: a case study of Minamisoma Municipal General Hospital after the Great
East Japan Earthquake. Disaster Med Public Health Prep. 2014;8:471-476. http://dx.doi.org/10.1017/dmp.2014.112.

3. Tsubokura M, Kato S, Morita T, et al. Assessment of the annual additional effective doses amongst Minamisoma children during the second year after the Fukushima Daiichi nuclear power plant disaster. PLoS One. 2015;10(6):e0129114. http://dx.doi.org/10.1371/journal. pone.0129114.

doi:10.1017/dmp.2015.180

\title{
Critical Guidelines for Health Care Workers Who Deploy to West Africa for the Ebola Response
}

\author{
Viroj Wiwanitkit, MD, FRFM
}

$\mathrm{T}$

The recent report "Academic Institutions' Critical Guidelines for Health Care Workers Who Deploy to West Africa for the Ebola Response and Future Crises" was very interesting. ${ }^{1}$ Cranmer et al mentioned a "lack of sufficient and qualified [health care workers]." In fact, a team of volunteers to work in West Africa assisting those affected by the outbreak is a good thing. However, good preparation for a team of volunteers before an actual mission is necessary. At least, there should be a short training course on the new disease before health care workers are allowed to enter the outbreak area. ${ }^{2}$ Patel et al noted that "existing community health programs can be used as a platform to train volunteer health advisors in times of epidemics for quick dissemination of vital health information in areas lacking adequate health infrastructure and personnel." ${ }^{\text {3 }}$ Finally, preparation for management of possible infected volunteer health care workers is required. There must be a good primary management and a referring back system.

\section{About the Authors}

Hainan Medical University, China (visiting); Faculty of Medicine, University of Nis, Serbia (visiting); Joseph Ayobabalola University, Nigeria (adjunct); and Dr DY Patil Medical University, India (honorary).
Correspondence and reprint requests to Prof Viroj Wiwanitkit, Wiwanitkit House, Bangkhae, Bangkok, Thailand 10160 (e-mail: wviroj@yahoo.com).

Published online: January 29, 2016.

\section{REFERENCES}

1. Cranmer H, Aschkenasy M, Wildes R, et al. Academic institutions' critical guidelines for health care workers who deploy to West Africa for the Ebola response and future crises. Disaster Med Public Health Prep. 2015;9(5):586-590.

2. Lupton K. Preparing nurses to work in Ebola treatment centres in Sierra Leone. Br J Nurs. 2015;24(3):168-172. http://dx.doi.org/10.12968/ bjon.2015.24.3.168.

3. Patel U, Pharr JR, Ihesiaba C, et al. Ebola outbreak in Nigeria: increasing Ebola knowledge of volunteer health advisors. Glob J Health Sci. 2015; 8(1):72-78. http://dx.doi.org/10.5539/gjhs.v8n1p72. 